\title{
Cultural Mediators and Gatekeepers
}

\section{Susanne Janssen ${ }^{1}$ and Marc Verboord}

(Dept. of Media and Communication, Erasmus University Rotterdam)

\begin{abstract}
The shaping influence of cultural mediators, in particular their legitimizing power, has led cultural scholars to coin them 'tastemakers', 'gatekeepers', 'surrogate consumers', 'reputational entrepreneurs', or even 'co-producers' of the work of art. Yet, in practice, mediators perform highly different and often distinct activities according to their particular contributions in the (increasingly) vertically differentiated process of cultural production. This article discusses the various roles and activities of cultural mediators, followed by a review of the role and impact of critics and other mediators in the production and consumption of culture.
\end{abstract}

Key words: Arts; Audiences; Critics; Consecration; Culture; Cultural consumption; Cultural field; Cultural intermediaries; Cultural mediators; Legitimation; Reputation; Reviewers.

\section{Introduction}

Cultural gatekeepers and mediators - such as publishers, film studios, gallery owners, critics or reviewers - , can be defined as those involved in the mediation between the production of cultural goods and the production of consumer tastes (Bourdieu, 1984).

With the rise of the market as the most important structure for cultural production and distribution, institutions and agents who are in effect mediators have taken on an increasingly

\footnotetext{
${ }^{1}$ Corresponding author: Susanne Janssen, Dept. of Media and Communication, Erasmus University Rotterdam, M8-04, P.O. Box 1738, NL-3000 DR Rotterdam, The Netherlands. Email: s.janssen@eshcc.eur.nl
} 
crucial role in the development of artistic careers and reputations as well as the formation of cultural tastes and consumption patterns. Cultural mediators became vital agents to artists, not only with respect to the immediate problem of economic survival and reaching an audience, but also for the valuation of their work and the establishment of their reputations.

The formative role of cultural mediators is not limited to traditional 'high' arts worlds by any means. They play an equally important part in the cultural industries, scouting and selecting creative talent (Caves, 2000; Hesmondhalgh, 2012), determining what creations are turned into marketable commodities and what products eventually reach audiences (Debenedetti, 2006; Hirsch, 1972).

This article reviews key concepts, findings, and developments in the social-scientific study of the role and impact of critics and other mediators in the production and consumption of culture. While we start with providing an overview of the various roles and activities of cultural mediators which are discerned in the literature, our main focus will be on how mediators -- in particular reviewers and critics -- affect symbolic production in the cultural field (e.g. reputations of artists, legitimacy of genres). Cultural mediators add symbolic value to culture, whether they are involved in the material production (e.g. publishers), distribution (e.g. art galleries), or evaluation (e.g. critics) of culture. Through their selective and evaluative activities they contribute to the 'production of the value of the work or, what amounts to the same thing, of the belief in the value of the work' (Bourdieu, 1996: 229) by virtue of the symbolic capital or prestige they have acquired as cultural experts. For other work on cultural mediators such as organizational studies or macrolevel analyses of power relations in the cultural industries, we refer to other entries such as those on Markets and Production of Culture.

We draw liberally upon work inspired by various research perspectives that have been developed by empirically oriented cultural scholars from the 1970s onwards, including the production-of-culture perspective (Peterson and Anand, 2004); art world research (Becker, 1982); field theory (Bourdieu, 1984, 1996; Van Rees and Dorleijn, 2001); artistic classification systems theory (DiMaggio, 1987); and neo-institutional theory (Dowd, 2011). Although these approaches have different points of departure, employ different concepts and methodologies, and focus on different aspects of cultural production and consumption, no clear-cut divisions exist between them. Many individual researchers and studies, with good reason, can be viewed as representative of more than one approach. It lies outside the scope of this article to detail similarities and 
differences among them.

It is most important in this context that they all have illuminated, in one way or another, the thoroughly social nature of cultural production. This refers to the way in which a variety of people are actually involved in the production of a work itself (Becker 1982), but also to the underlying processes and conditions which make the production possible, and those which determine its subsequent course.

\section{Role of cultural mediators in the lifecycle of cultural products}

Most studies on cultural mediators have focused on how they impact artistic careers and reputations or influence the preferences and tastes of cultural consumers. The modus operandi of cultural mediators themselves has received somewhat less attention. Cultural mediators generally operate in fields characterized by turbulence, a huge supply of cultural offerings and aspiring artists, (demand) uncertainty, and a lack of unequivocal quality standards. In order to understand how they cope with these challenges and constraints we need to consider the organizational and institutional settings in which they perform their various mediating activities.

The past decades witnessed a flood of research on how mediators in the field of art and culture shape individual works and whole careers. The shaping influence of cultural mediators, in particular their legitimizing power, has led sociologists to coin them 'tastemakers', 'gatekeepers', 'surrogate consumers', 'reputational entrepreneurs', or even 'co-producers' of the work of art. Yet, in reality mediators perform highly different and often distinct activities according to their particular contributions in the (increasingly) vertically differentiated process of cultural production. Taking the production cycle of cultural products as a starting point, we can distinguish (at least) seven widespread mediating practices which substantially inform the modus operandi of cultural mediators.

\section{Selecting from the supply (Gatekeeping)}

One of the most studied aspects in the work of cultural mediators relates to what constitutes an essential dilemma in cultural production: of all the artists who turn to cultural organizations or sponsors to seek financial help in getting their products to an audience, only a limited number can actually receive such sponsorship. Agents such as publishers, A\&R staff of record companies, or 
museum curators are responsible for making a first selection from the artists who are deemed worthy of being produced: they are the gatekeepers of the artistic field.

The term 'gatekeeping' has been applied when the focus is on judgments whether to admit persons or works into a cultural field; it has to do with accepting or rejecting works or their creators and the consequences of these choices for subsequent works and creators. Driving forces behind gatekeepers' decisions range from political and moral concerns, commercial interests, to 'purely' aesthetic motives. In most cases, they consist of a mixture of these.

The concept originates primarily from research into news production (Shoemaker and Vos, 2009), but it can be applied more or less equally to other areas of cultural production.

Gatekeeping refers to the capacity of mediators to exclude or promote. However, cultural industries from book publishing to television regularly make decisions other than choose/reject, altering or recontextualizing works at different stages of the production process. When the focus is on the way that works are changed as they move from being ideas to being finished products, the term decision making is more appropriate (Peterson and Anand, 2004). In the music industry, the original ideas of song-writers are filtered through music publishers' ideas concerning presentation (especially artist and style), which then play a part in promoting the product in several different markets. Processing takes place on the basis of a prediction about what the next 'gatekeeper' in the chain will think, the key being the overall product image.

It should be noted that most 'gatekeepers' are not passively waiting for new talents to submit their work. Research into the literary field has for instance shown how acquisition editors at publishing houses employ various search strategies (e.g. befriended foreign colleagues, agents, scouts, book auctions) to find the authors they want to publish (Franssen and Kuipers, 2013; Thompson, 2010). Similarly, in the music industries A\&R managers or talent buyers in the live music scene actively scout for talent (Foster et al., 2011; Negus, 1999).

\section{Co-creating / editing}

The next step in the production cycle is 'co-creating' or 'editing', all the activities and feedbacks that mediators provide to artists to meet standards of artistic conventions or commercial expectations. These practices generally receive much less academic attention than gatekeeping. One reason is that, as the previous examples showed, the boundaries between gatekeeping and 
co-creating are often diffuse. As 'co-producers' many gatekeepers guide artists through the production process, shaping the content of cultural products (Becker, 1982; Peterson and Anand, 2004). Another reason, however, appears to be persistent influence of what Bourdieu called the 'charismatic ideology': the tendency to interpret all works of art as outbursts of individual creativity thereby downplaying the contributions of relevant others. Still, most cultural fields contain some form of co-creation: the sound of music records is adapted by producers and technicians, literary texts are fine-tuned by editors or translated by translators, and in film and television producers and directors exert their influence on various levels: script, actors, photography, special effects, etc.

\section{Connecting / networking}

Within a sector that is as strongly dependent on collaboration as the cultural sector (Becker, 1982), mediators are almost by definition connectors. The gatekeepers who scout for talent via their networks (see above) provide an obvious example. Yet some studies have highlighted how certain cultural mediators are specialized in connecting. We mention some examples. Literary agents have become powerful players in the field of fiction book publishing (Thompson, 2010). They negotiate the deals that authors make with publishers, but at the same time also actively manage their portfolio of author clients to establish their own reputation. This form of cultural brokerage -- matching authors and publishers of similar standing -- ultimately influences which type of authors are being published in the field (not unlike the influence of song-pluggers in the music industry).

Art dealers, gallery owners, auctioneers, and curators play a similar part in the visual arts, determining which works, artists, and schools come before the public as well as urging artists to produce certain types of work (Moulin, 1987; Quemin 1997; Velthuis, 2005). Like independent agents spanning organizational boundaries in the recording industry, dealers seek artistic 'talent' in one group and corresponding buyers in a different group. Successful artists are those who recognize the privileged 'entrepreneurial' position of their dealers and listen to their feedback about clients' aesthetic sensibilities.

\section{Selling / marketing}

In the final stage of the production process we find mediators who sell or market the products, 
and thus establish the contact with the audience. Production organizations in the cultural industries, such as publishing, music or movie companies, depend for the successful dissemination of their products on media gatekeepers whose 'free' publicity' is often more effective than advertising because of its alleged objectivity. Typical strategies to cope with constraints posed by media gatekeepers include the employment of specialized promotion and public relations personnel, overproduction, differential promotion of new products, and cooptation of media gatekeepers (Hirsch, 1972). The latter strategy is often at odds with the interests of media organizations, which are supposed to deploy independent standards in their selection and assessment of cultural products (rather than promoting items which cultural organization put forward), while at the same time they have to attune their coverage to the target audiences of their advertisers. Hence, the efforts of cultural organizations to influence media gatekeepers vary to the extent that media coverage is vital for generating consumer demand.

\section{Distributing}

In most cultural fields, distribution comprises a form of mediation situated outside production. A number of research themes have emerged in the literature. First of all, the continuing competition between producers and distributors for economic dominance due to their interdependence: producers need the network to bring their products to the audience; distributors need attractive products to offer the audience. Fluctuations in the market power of these institutions inform takeovers and subsequent vertical integration. Another, more micro-oriented approach focuses on how distributors shape the production of culture. Thompson (2010) for instance showed how the rise of book retailers changed the practices of publishers and ultimately the books that are released. Of course, distribution has become an even more timely research theme for mass-produced products as a consequence of digitalization (see later).

Whereas cultural industries studies routinely refer to distribution as the process of bringing products into circulation for sale (e.g. stores, galleries), display (film exhibitors), or performance (theaters), some institutions primarily seek to make culture more accessible (e.g. libraries and art loan organizations). Other ways of disseminating culture impact symbolic production. Festivals and biennales have become events where like-minded audiences gather to experience a special selection of products generally in a relaxed setting with food, drinks, and 
other entertainment, but whose most successful exponents propel high status (e.g. Cannes film festival or the Venice Biennale).

One can also think of educational institutions and art histories that mediate the relationship between artists and audiences. Curricula and cultural encyclopedias emphasize some works to such an extent that they become institutionalized as canonical art. School books tell students whom to read and what kinds of things to say about literary texts. Meanwhile, educators' book orders help to determine which books remain available and enjoy regular updates.

\section{Evaluating, classifying and meaning making}

Many agents and organizations in the cultural field have no immediate interest in the artistic or commercial success of cultural products, but aim to judge the value and/or meaning of cultural endeavors. Most of these mediators (e.g. reviewers, critics, scholars) are situated in the field of media and academia. While Kees van Rees $(1983,1989)$ was one of the first to analyze the threestep procedure of critics -- description, interpretation, evaluation -- and its problematic connection to 'critic's connoisseurship', many researchers since have been working on cultural evaluation.

We will discuss the work of reviewers and critics in more detail in section 2, but would like to point out some other adjacent roads this research has taken. For instance, the traditionally humanistic take on how art can be described and interpreted has been rephrased and readdressed using entirely different methodologies, as the study of cultural meaning by cultural sociologists such as John Mohr (See entry on Formal Methods of Cultural Analysis) and Wendy Griswold. Griswold has demonstrated in various publications how mediators in the literary field 'fabricate' cultural meaning from socially shaped presuppositions in close dialogue with the particular characteristics of the cultural object. Another strand of research addresses cultural classification systems. Inspired by the work of Paul DiMaggio (1987) and others, scholars have started to unravel how mediators create, negotiate and transform genre classifications, thereby impacting audience perceptions and market success (e.g. Zuckerman \& Kim, 2003; see Entry on Classifications in Music). 


\section{Censoring, protecting and supporting}

An entirely different type of mediating concerns censoring and other policy-related instruments. Political and legal constraints on artists' work and careers belong to the pervasive themes in the sociology of the arts (Alexander and Rueschemeyer, 2005; Peterson and Anand, 2004). Government bodies and laws, either through the carrot of support or the stick of censorship, accomplish exclusion and channeling in the visual arts, literature, and other cultural domains. Many studies have focused on how censorship operates to reduce freedom of expression, but censorship may also provide the stimulus for more complex symbol expression, illusion, euphemism, analogies, and the like.

Policy agents can also protect and support particular types of artists and products. In recent decades, three important research themes received attention. First, cultural globalization studies have highlighted how countries differ in taking legislative measures to protect local artists from competition from foreign artists. Examples are the installment of quota for national music to be played on the radio, or the subsidizing of the national film industry. Another emerging theme, which is directly related to changing patterns in cultural consumption, concerns the tension between highbrow and popular arts. Whereas highbrow art forms such as classical music and theater generally receive the bulk of governmental support, it is increasingly signaled in the media that their audience generally represents just a small, relatively affluent portion of society. A third much debated policy issue is how to retain a meaningful copyright system that protects artists and producers from the unlawful reproduction or distribution of their works while at the same time preserving the innovative power of the Internet and the free flow of information.

\section{The impact of critics and other mediators on symbolic production}

\subsection{Institutional context of cultural evaluation}

Cultural mediators are also confronted with challenges and risks of a different nature, which have to do with the institutional setting in which they perform their selective and evaluative tasks. Their selections and evaluations do not only affect the reputations of cultural products and their makers, but also their own status and authority ('their symbolic capital') in the field.

This applies to all professional experts involved in the selection and valuation of cultural products - talent scouts, agents, publishers, film or music producers, curators, theater programmers, etc. - but it holds a fortiori for critics and reviewers whose selections and 
evaluations are made publicly available. As Bourdieu (1983: 317) points out: 'Every critical affirmation contains, on the one hand, a recognition of the value of the work which occasions it, which is thus designated as worthy object of legitimate discourse (...), and, on the other hand, an affirmation of its own legitimacy. Every critic declares not only his judgment of the work, but also his claim to the right to talk about it and judge it'.

Like all cultural experts, critics need to gain recognition as connoisseur and to inspire confidence in their capacity to assess the properties and value of a work. However, critics lack a reliable instrument to assess aesthetic qualities in an unequivocal way and no objective agency or procedure can prove their evaluations true or false (Van Rees, 1989). Moreover, they have to perform their job in a context of numerous cultural offerings and limited media space, keeping in mind the audience their media is supposed to serve.

That is why critics take into account various institutional quality indicators in their selection and assessment of new cultural products (Janssen, 1997). Particularly, they consider the reputation of the cultural organization (e.g. the publisher, film company, music label, theatre, or gallery) that brings a work or artist on the market and previous critical assessments of an artist's work (i.e. the artist's reputation). They also take due note of the cultural coverage of other media outlets, notably those which are active in the same market segment. Moreover, they strongly rely on genre classifications and genre conventions (Glynn and Lounsbury, 2005; Zuckerman and Kim, 2003), as well as on 'background and 'inside' information they receive through their contacts with representatives of cultural organizations, peers, and other experts in their professional networks (Bielby and Bielby, 1994).

In considering the institutional 'clues' provided by established reputations, peer opinions , genre distinctions, competitors, and professional networks, critics reduce the uncertainty as to which works deserve their attention and how to express this attention . In doing so, they enhance the odds that their assessments will be taken seriously or even get adopted by their fellow critics and other experts. Ultimately, the authority of critics and other mediators depends on the credits they have earned by making 'successful' evaluations, i.e. evaluations that were adopted by other experts in the field and are trusted by the audiences they serve. This does not imply that critics should always comply with their peers. On the contrary, they have to distinguish themselves in order to gain prestige as a connoisseur. By developing perspectives which qualify previous critical tenets or by deviating in their evaluations or their choice of works for discussion critics may make 
their mark as 'independent' experts. However, the institutional framework within which they function poses limits to the scope for dissent (Janssen, 1997; Van Rees, 1989).

The above strategies to minimize uncertainties and risks in critic's assessment of cultural products are also omnipresent in the decision making processes of other cultural mediators. Like critics, other mediators base their selections and decisions to a large extent on the institutional knowledge and contextual information they have about cultural products and their creators, including their classification into particular genres; the recognition creators have thus far received from various actors in the field; the reputations of their organizational sponsors; the choices made by competitors; and the information and opinions of members of their professional networks.

\subsection{Reputation making and cultural consecration}

Critics and other experts play a crucial role in the establishment and survival of artistic reputations. Artists and their critic-advocates seeking recognition make claims of creativity, quality, innovativeness, excellence - that is 'talent' or 'genius'. While sociological theory and method are not very useful in identifying 'talent' or 'genius' in works or their makers, they have proved very helpful in demystifying canon formation, the processes by which claims of 'genius' or 'quality' come to be agreed upon and reputations established (Menger, 2014).

Art critics, curators, and gallery owners appear to 'discover' new artistic geniuses all the time in a promotional role that plays a crucial part in the distribution of paintings to sophisticated buyers who would not dream of being influenced by advertising (Moulin, 1987). Studies of the contemporary art market (Velthuis, 2005) underline the promotional capacity of art experts as well as their key role in the construction of artistic value.

How the value and nature of literary works come to be agreed upon by critics and writers' reputations established is illuminated in many studies (Berkers et al., 2013; Janssen, 1997; Van Rees and Dorleijn, 2001). Van Rees (1983), for example, details how the complementary activities reviewers, essayists, and academic critics determine to a great extent which texts are regarded as legitimate forms of fiction; what rank they are supposed to occupy within the hierarchy of literary works; and what statements count as proper and relevant ways of characterizing these texts.

Critics are also key agents in acts and processes of cultural 'consecration', whereby a few artists and works are identified and set apart from others in their field as exceptionally valuable 
and gain an exemplary and celebrated status. Cultural consecration refers to the establishment of a 'magical division' between the 'pure' and 'sacred' cultural offerings, on the one side, and the 'facile' or "profane" products on the other (Bourdieu, 1984). Critical attention, peer recognition, and public acclaim all affect the odds that some artists or works are eventually counted among the 'greatest of all time'. Cultural scholars have examined acts and processes of consecration in a variety of cultural fields including literature (Van Rees and Dorleijn, 2001), film (Allen and Lincoln, 2004), visual arts (Ginsburg and Weijers), classical music (Dowd, 2011) and popular music (Bennet, 2009). This research has shown that critical recognition is especially important in the consecration of cultural producers and their works.

\subsection{Cultural legitimation}

'Retrospective' consecration of some works and artists also takes place because art world members seek to raise the prestige of their field by highlighting "elements of their pasts which are most clearly artistic, while suppressing less desirable ancestors" (Becker, 1982, p. 339). In rewriting the history of their field, critics and other experts try to show it has always generated artistically valuable work. Thus retrospective cultural consecration not merely singles out the greatest works or artists in a field but is also a means of bestowing legitimacy upon an entire field of cultural production.

The processes and mechanisms through which cultural forms attain artistic legitimacy have garnered much attention over the past decades. Cultural and organizational scholars have highlighted the role of social change in creating an 'opportunity space' for ascendant art forms (Baumann, 2007; DiMaggio, 1992). Claims of cultural value emerge in a wider social context, which may change over time in terms of the degree of competition, the availability of alternatives or substitutes, public interest, etcetera, and as such affect whether particular products and genres will gain cultural legitimacy. Cultural legitimation is also contingent upon the institutional and organizational resources (e.g. money, labor, knowledge, networks) that art world members manage to mobilize (Baumann, 2007; Becker, 1982).

A third key factor in processes of cultural legitimation is the development of a legitimating ideology that substantiates claims to artistic value and lends symbolic prestige to a cultural field (Baumann, 2007; Becker, 1982; Bourdieu, 1984; Van Rees, 1983). Artistic value attribution calls for an explanation of why particular cultural objects or genres can be deemed 
artistically important (Baumann, 2007). Media critics and reviewers -drawing on academic criticism - play a central role in developing and disseminating such explanations of artistic worth and are thus crucial agents in elevating the status of cultural forms and genres.

The impact of critics and reviewers may appear more salient in traditional high art worlds where their expert status is institutionally embedded and reinforced through academic programmes and educationally curricula (Bauman, 2007; Bourdieu, 1984; Van Rees and Dorleijn, 2001). However, the impact of media attention and critical discourse is also crucial in the valorization and aesthetic mobility of a variety of popular cultural forms.

Bauman (2007) demonstrates how the intellectualizing discourse of film critics, who over the years increasingly employed terminology (e.g. art, genius) and reviewing techniques (e.g. mentions and comparisons of directors) associated with high culture, contributed to the cultural legitimation of film in the United States. The development of this 'high art discourse' in film reviewing paved the way for the wider acceptance of film as art as it resonated with the cultural capital of higher educated audiences, peer critics and other members of the field. Critics and reviewers have been found to play a similar role in the valorization of a variety of other cultural forms (Janssen et al., 2011), including jazz, popular music, television, and fashion.

Meanwhile, the past decades also witnessed the rise of alternative, 'popular' forms of critical discourse, albeit often in less prestigious settings. Pop music reviews, for example, are often characterized by a popular aesthetic discourse, in which functionality, entertainment and other more audience oriented criteria prevail over high arts standards (Van Venrooij and Schmutz, 2010). Likewise, Kersten and Bielby (2012) find that contemporary film reviews "incorporate aesthetic elements drawn from popular interests as well as elite art considerations, thereby complicating critics' aesthetic systems and analysts' classificatory schemes."

\subsection{Impact on cultural tastes, consumer behavior, commercial success}

Many studies have found an influence of media critics and reviewers on consumer preferences and the commercial performance of cultural products, notably in the field of film and the performing arts (Debenedetti, 2006). When the supply is large, time is scarce, and markets are flooded with commercial information, consumers can draw on critical evaluations to simplify the decision-making process and reduce the basic uncertainty associated with experiential products of which the quality is hard to assess prior to consumption. Nonetheless, whether critics' opinions 
influence the commercial success of products remains contested and seems to depend on specific features of the product and/or the specific audience at which the product is targeted (Gemser et al., 2007). Individual audience characteristics also play a part. Cultural participants who are more involved or have more expertise are more likely to use reviews than others.

The correlation between critical evaluation and commercial success has been found to be particularly strong for cultural products that have weak signaling properties for the general public (e.g. lack a high-profile cast, special effects, exotic locations and/or elaborate sets), low-budget works that cannot rely heavily on promotional devices (such as previews, trailers and advertisements) to shape consumer preferences and belong to unfamiliar genres (Debenedetti, 2006).

For blockbuster movies targeting large audiences, the amount of media coverage has a stronger impact on box office performance than whether reviews contain positive evaluations. However, in the case of art house movies and other films that cater for artistically oriented audiences, critical evaluations and recommendations have positive effects on commercial success (Gemser et al., 2007). Thus, whereas 'art' films need positive reviews to gain industry recognition, the commercial success of mainstream films depends on being noticed and creating a 'buzz' (Holbrook and Addis, 2008).

These findings agree with socially embedded patterns of media use and cultural tastes, as well as with the institutional embeddedness of critics. A preference for cultural products of a particular degree of legitimacy often coincides with using media enjoying a similar degree of legitimacy (Bennett et al., 2009; Bourdieu, 1984). The influence of a review thus depends on the critic's or medium's social and cultural proximity to the reader. Cultural participants who have a taste for 'highbrow' cultural products often read the print media in which such products receive extensive coverage, (e.g. 'quality' newspapers) and via processes of self-selection they are [thus] likely to take critics' judgments into consideration (Janssen et al., 2011; Verboord, 2013).

\section{Cross-cultural exchange}

Cultural mediators are also important when it comes to the international mobility, visibility, and reception of cultural products (Crane, Kawashima and Kawaski, 2002). Griswold (1987) considers the export of meaning beyond national borders and the transformations of meaning which occur through this process. Comparing American, British, and West Indian reviews of the 
work of the Barbadian novelist George Lamming, she finds stunning cross-cultural divergences. Race is highlighted in American reviews of Lamming's novels, yet virtually ignored in British discussions, which focus instead on the novels' language and literary qualities.

In spite of ongoing 'cultural globalization', and in contrast to the so-called 'contra-flow' argument, coverage of foreign culture in European and U.S. elite newspapers has not become much more global between 1955 and 2005 (Janssen et al., 2008). The global diversity of cultural coverage has increased, but international art coverage has remained largely confined to a select group of countries belonging to the core of the cultural world system, while domestic cultural products continue to be prominently featured in the cultural coverage of elite newspapers. These findings, which are in line with those of many other empirical studies, underscore how cultural mediators, can enhance the enduring imbalances in international cultural exchanges, and, may promote and sustain local cultural production.

Of course, they can also serve as 'gatemakers' pushing the boundaries of international cultural traffic, as is evidenced, for example, by the foreign literature series that French publishers developed with the help of the French ministry of culture in the 2000s, featuring translations from more than 30 small and peripheral languages into French (Sapiro, 2010). Similarly, Kuipers (2011) shows how television buyers who mediate and maintain relations between the national and transnational television field, play an important role in the diffusion of quality standards, practices, and programs into national fields of television production, and, from there, to consumers.

\section{Developments impacting the role and authority of cultural mediators}

Increasing globalization has enhanced the risks and uncertainties inherent in the work of cultural mediators, such as publishers, curators, festival programmers, casting agencies, music producers, and television broadcasters. In addition to an already huge supply of domestic products, cultural mediators are confronted with an overwhelming abundance and diversity of foreign cultural offerings, for which the audience interest, market potential, and artistic merits are difficult to assess.

At the same time, due to the advancing commercialization of cultural production fields, cultural mediators face heightened competition, both in national cultural fields and the fast paced, highly competitive transnational cultural arenas in which the odds of success and recognition are very unequal for players from different countries and places. 
The intensified use and increased interactivity of the Internet have transformed the ways in which cultural information is being searched, created and valued (see also Entry Internet and Culture). In recent years, cultural consumers across the globe have increasingly turned toward the web: to purchase cultural products at online shops; download and upload music, videos, films and other content; rate and review cultural products; get advice and recommendations from other consumers; and engage in debates and discussions on social network sites. Many cultural websites prosper through participatory practices by audiences. Peer-to-peer communication enables audiences to create, share and evaluate user-generated content and actively participate in cultural opinion making.

Increasingly, Internet users thus seem to be moving away from institutional gatekeepers and experts and instead refer to information provided by other Internet users. This trend does not merely undermine the authority of these cultural mediators, but also appears to erode the entire underlying system in which institutionally embedded experts decide on the value and legitimacy of cultural artifacts in society (Verboord, 2013). 'Bottom-up' practices of selecting and evaluating culture challenge the existent 'hierarchical' model of cultural valorization, in which critics and other mediators play a pivotal role by legitimizing the culture from the higher status groups through their cultural authority.

However, this development is not just caused by the rise of new media technologies and associated opportunities and practices for cultural consumers, but is deeply rooted in wider societal and cultural changes that occurred since the 1960s in Western societies. The democratization of higher education, the emancipation of minorities (women, youngsters, ethnic, racial and sexual minorities), increased social mobility and heterogeneity contributed to the erosion of traditional cultural hierarchies and the rise of omnivorous taste patterns, while it also enabled social climbers and minorities to 'import' their tastes into higher circles and to bestow prestige upon their preferred genres. Processes of individualization have made people less prone to subscribe to traditional cultural hierarchies, collective taste patterns and the judgments of cultural experts, but, instead, increasingly require them to choose individually and to show individual authenticity in their expression of taste (Janssen et al., 2011).

These developments profoundly affect the work of critics and other cultural mediators. As the institutional consensus and institutionally embedded authority through which they used to operate declines, their position becomes more dependent on the uncertainties and vagaries of the 
market, requiring them to stay more closely attuned to or follow audience interests and consumer preferences.

\section{Future research}

Many avenues for further research relate to the fast changing cultural landscape in which mediators maneuver. One obvious subject for future research already mentioned concerns the rise of the Internet. Many forms of mediating appear to become obsolete as technologies enable artists to bypass mediators. Publishers, record companies, book stores, record stores, newspapers: they are all under pressure, and how their possible disappearance would impact the way culture, and cultural value, is being produced is far from clear.

How increased globalization and the emergence of transnational cultural fields transform the role and practices of cultural mediators, and how this plays out, at the local and transnational level, for agents from different countries and places across the globe, are other issues which definitely call for further research.

Yet also other developments deserve attention: the increasing segmentation and differentiation of cultural work (e.g. the rise of live music industries; literary agents), the advance of oligopolies (in music and film production) and monopolies (online: Google, Amazon; offline: LiveNation), and the decreasing support for the arts among general populations, which impacts not only the work and careers of artists but also the professional lives of the manifold mediators who contribute to the highly differentiated processes of cultural production and distribution.

\section{Literature}

Alexander, V. D., Rueschemeyer, M., 2005. Art and the State: The Visual Arts in Comparative Perspective. Palgrave Macmillan.

Allen, M. P., Lincoln, A. E., 2004, Critical discourse and the cultural consecration of American films. Social Forces 82, 871-894.

Baumann, S., 2007. Hollywood Highbrow. From Entertainment to Art. Princeton, Princeton University Press, Princeton.

Becker, H. 1982. Art Worlds. University of California Press, Berkeley.

Bennett, A. 2009. "Heritage rock": Rock music, representation and heritage discourse. Poetics 37, 474-489. 
Bennett, T., Savage, M., Silva, E. B., Warde, A., Gayo-Cal, M., Wright, D., 2009. Culture, Class, Distinction. Routledge, London.

Berkers, P., Janssen, S., Verboord, M., 2014. Assimilation into the literary mainstream? The classification of ethnic minority authors in newspaper reviews in the United States, the Netherlands and Germany, Cultural Sociology 8 (1), 25-44.

Bielby, W. T., Bielby, D. D., 1994. All hits are flukes: Institutionalized decision making and the rhetoric of network prime-time program development. American Journal of Sociology 9 , 1287-1313.

Bourdieu, P., 1984. Distinction. A Social Critique of the Judgment of Taste. Routledge \& Kegan and Paul Ltd, London.

Bourdieu, P., 1996. The Rules of Art: Genesis and Structure of the Literary Field. Stanford University Press, Stanford, CA.

Caves, R.E., 2000. Creative Industries. Harvard University Press, Cambridge, MA.

Crane, D., Kawashima, N., Kawasaki, K. (Eds.), 2002. Global Culture. Media, Arts, Policy and Globalization. Routlegde, London

Debenedetti, S., 2006. The role of media critics in the cultural industries. International Journal of Arts Management 8, 30-42.

DiMaggio, P., 1987. Classification in art. American Sociological Review 52, 440-455.

DiMaggio, P., 1992. Cultural boundaries and structural change: The extension of the high culture model to theater, opera, and the dance, 1900-1940, in Lamont, M., Fournier, M. (Eds.), Cultivating Differences. University of Chicago Press, Chicago, pp. 21-57

Dowd, T.J., 2011. Production and producers of lifestyles. Kölner Zeitschrift für Soziologie und Sozialpsychologie 63 (51), 113-138.

Franssen, T., Kuipers, G., 2013. Coping with uncertainty, abundance and strife: Decision-making processes of Dutch acquisition editors in the global market for translations. Poetics 41, 4874.

Gemser, G., van Oostrum, M., Leenders, M.A.A.M., 2007. The impact of film reviews on the box office performance of art house vs. mainstream motion pictures. Journal of Cultural Economics 31, 43-63.

Ginsburgh, V., Weyers, S., 2006. Persistence and fashion in art Italian Renaissance from Vasari to Berenson and beyond. Poetics 34, 24-44. 
Griswold, W., 1987. The fabrication of meaning: literary interpretation in the United States, Great Britain, and the West Indies. American Journal of Sociology, 1077-1117.

Griswold, W., 1992. The writing on the mud wall: Nigerian novels and the imaginary village. American Sociological Review, 709-724.

Foster, P., Borgatti, S. P., \& Jones, C., 2011. Gatekeeper search and selection strategies: Relational and network governance in a cultural market. Poetics 39, 247-265.

Hesmondhalgh, D., 2012. The Cultural Industries (Third edition). Sage, Los Angeles

Hirsch, P. M., 1972. Processing fads and fashions: An organization-set analysis of cultural industry systems. American Journal of Sociology, 639-659.

Holbrook, M. B., Addis, M., 2008. Art versus commerce in the movie industry: a two-path model of motion-picture success. Journal of Cultural Economics 32, 87-107.

Janssen, S.,1997. Reviewing as social practice: Institutional constraints on critics' attention for contemporary fiction. Poetics , 275-297.

Janssen, S., Verboord, M., Kuipers, G., 2008. Cultural globalization and arts journalism. American Sociological Review 73, 719-740.

Janssen, S., Verboord, M., Kuipers, G. 2011. Comparing cultural classification: high and popular arts in European and US newspapers, 1955-2005. Kölner Zeitschrift für Soziologie undSozialpsychologie 63 (51), 139-168.

Kersten, A., Bielby, D. D., 2012. Film discourse on the praised and acclaimed: Reviewing criteria in the United States and United Kingdom. Popular Communication10, 183-200.

Kuipers, G., 2011. Cultural globalization as the emergence of a transnational cultural field: Transnational television and national media landscapes in four European countries. American Behavioral Scientist 55, 541-557.

Menger, P., 2014. The Economics of Creativity. Art and Achievement under Uncertainty. Harvard University Press, Cambridge, MA.

Moulin, R., 1987. The French Art Market: A sociological view. Rutgers University Press, New Brunswick, NJ.

Negus, K., 1999. Music Genres and Corporate Cultures. Routledge, London.

Peterson, R.A., Anand, N., 2004. The production of culture perspective. Annual Review of Sociology 30, 311-334.

Quemin, A., 1997. Les commissaires-priseurs: la mutation d'une profession. Ed Anthropos, Paris. 
Sapiro, G., 2010. Globalization and cultural diversity in the book market: The case of literary translations in the US and in France. Poetics 38, 419-439.

Shoemaker, P.J., Vos, T.P. 2009. Gatekeeping Theory. Routledge, London.

Thompson, J. B., 2010. Merchants of Culture. Polity, London.

Van Rees, C.J., 1983. How a literary work becomes a masterpiece. Poetics 12, 397-418.

Van Rees, C. J.,1989. The institutional foundation of a critic's connoisseurship. Poetics18, 179198.

Van Rees, C.J., Dorleijn, G., 2001. The eighteenth-century literary field in Western Europe: interdependence of material and symbolic production and consumption. Poetics 28, 331348.

Van Venrooij, A., Schmutz, V., 2010. The evaluation of popular music in the United States, Germany and the Netherlands: A comparison of the use of high art and popular aesthetic criteria. Cultural Sociology 4, 395-421.

Velthuis, O., 2005. Talking Prices: Symbolic Meanings of Prices on the Market for Contemporary Art. Princeton University Press, Princeton, NJ.

Verboord, M., 2013. The impact of peer-produced criticism on cultural evaluation. New Media \& Society, first published on July 3, 2013 as doi:10.1177/1461444813495164.

Zuckerman, E.W., Tai-Young Kim, T.Y., 2003. The critical trade-off: identity assignment and box-office success in the feature film industry. Industrial and Corporate Change 12, 2767. 